\title{
Slenderness-based design for sigma sections subjected to interior one flange loading
}

\author{
Meshal Almatrafi ${ }^{1}$, Marios Theofanous ${ }^{1, *}$, Marina Bock ${ }^{2}$, Samir Dirar ${ }^{1}$ \\ ${ }^{1}$ Department of Civil Engineering, University of Birmingham, Edgbaston B15 2TT, UK \\ ${ }^{2}$ School of Architecture and Built Environment, University of Wolverhampton, Wolverhampton, WV1 \\ 1LY, UK \\ * Corresponding author, Department of Civil Engineering, University of Birmingham, Edgbaston B15 2TT, \\ UK, Email address: m.theofanous@bham.ac.uk
}

\begin{abstract}
Due to their thin-walled nature and complex geometry, cold-formed steel purlins are prone to a variety of instabilities. Sigma purlins are a family of cold-formed steel members with folding-lines along their webs. The non-straight geometry of their web is beneficial in terms of reducing the susceptibility of the web to local buckling, however, it increases their susceptibility to web crippling when the purlins are subjected to concentrated transverse loads and hence it may reduce their overall moment resistance. This paper reports a series of experiments on sigma purlins under the interiorone-flange (IOF) loading condition. Two different section geometries and three different bearing plate widths were examined. To investigate further the effect of web geometry on the IOF web crippling strength of sigma sections, an FE model was developed and validated against the reported test results. Following successful replication of the experimental observations, a comprehensive parametric study was performed, and several sigma sections covering a wide range of crosssectional geometries and slenderness were numerically modelled. Finally, a slenderness-based (or direct strength) design approach previously developed for the web crippling design of channel and hat sections is extended to sigma sections.
\end{abstract}

\section{Keywords}

Cold-formed steel; web crippling; experiments; FE model; Slenderness; Lipped sigma sections; Design; Interior one flange loading

\section{Introduction}

Traditionally purlins are utilised as secondary steel members transferring the loads of cladding, snow and wind to the primary steel structure. Purlins are primarily loaded by uniformly distributed loads, hence their geometry is optimized to resist local and distortional buckling, with little regard given to failure modes such as web crippling which can occur in the presence of concentrated loads. However, due to their high strength-to-weight ratio, additional applications of cold-formed steel members have been pursued by cold-formed steel section manufacturers, thus necessitating the study of the response of highly optimised sections under loads they have not been optimised to resist. A typical example of highly optimised cold-formed steel section geometry is the family of sigma section purlins which employs folding lines along their webs. The non-straight geometry of their web is beneficial in terms of reducing the slenderness of the web plated element, however, it increases their susceptibility to web crippling in case the purlins are subjected to concentrated transverse loads and consequently, it reduces their overall moment resistance. Therefore, the structural behaviour of sigma sections when subjected to web crippling warrants further research to enable these sections to be used in applications involving concentrated point loads.

Web crippling is defined as the occurrence of localised failure at the points of concentrated load or supports where the stresses are localised. Studying the various cross-sectional instabilities of coldformed steel members theoretically is very complex as many factors are involved, such as the initial geometric imperfections of the plated elements, load eccentricities, effect of curved corner regions, material yielding [1]. Therefore, the first web crippling investigations were mainly experimental. 
The first article found in the literature was conducted in 1946 by Winter and Pian [2] who experimentally investigated cold-formed steel I-beams and proposed four different loading conditions to study the effect of web crippling. These loading conditions are the end-one-flange (EOF), the interior-one-flange (IOF), the end-two-flange (ETF), and the interior two-flange (ITF) as illustrated in Fig. 1. Based on their experimental work, empirical equations for web crippling design were recommended and adopted in the earlier version of the American standard AISI [3]. Following Winter and Pian [2] investigation, many researches between the 1950s and 1990s conducted tests on different cross-sections such as Z-sections [4,5,6,7], channel sections [4,8,9,10,11] I-sections [5,6,8], Hat sections $[6,7,12,13,14]$ and multi web sections (sheeting profiles) $[6,12,13,15,16,17]$. All these test results were gathered in [4] where fully empiric design provisions were derived for all four load cases and adopted in a more recent version of the AISI [18]. To date, the current version of the AISI, which is the NAS S100-16 [19], still employs the four loading conditions proposed by Winter and Pian [2]. In Europe, the part of Eurocode dealing with cold-formed steel, the EN 1993-1-3 [20], has adopted an equivalent system based on categories where category one corresponds to the EOF, ETF and ITF loading conditions and category two corresponds to the IOF loading condition. Other design standards for cold-formed steel such as the New Zealand AS/NZS 4600:2018 [21] are based on the same empiric principle. Although the design of rectangular and square hollow sections is not included in the above standards and codes, experimental research was also carried out before the 2000s $[22,23]$.

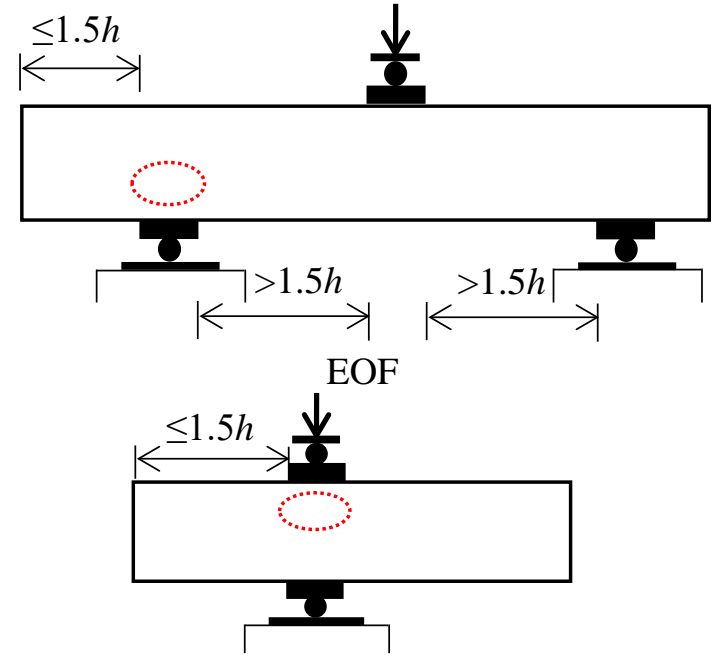

ETF
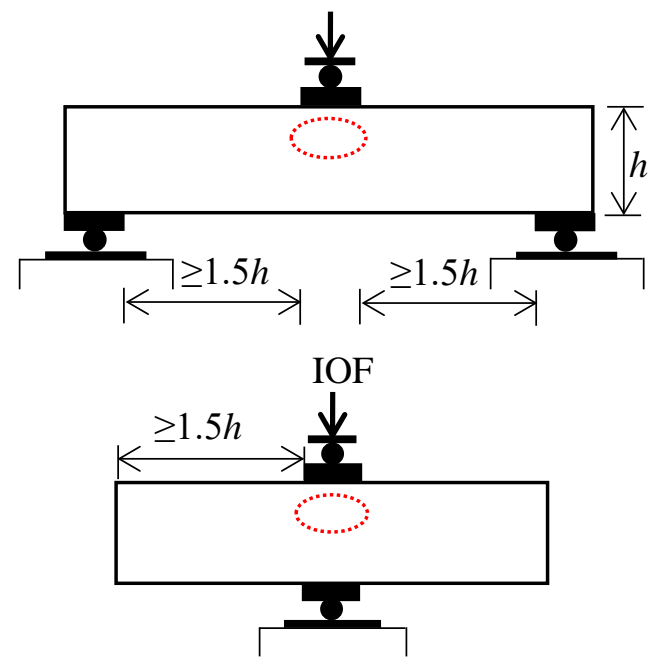

ITF

Fig. 1. Web crippling loading conditions (a) EOF, (b) IOF, (c) ETF, (d) ITF

Owing to the complex and physical nonlinearities associated with web crippling problems, it was not until the mid 1980s when the first numerical studies were reported by Santaputra [24] and Sharp [25]. Yet, web crippling simulations required long computational times that could result in unfeasible simulations [14,26]. This was overcome with the advancements in computing and numerical modelling software in the late 1990s and early 2000s making therefore possible to conduct the first parametric studies successfully [27-30]. Since then, several research studies on cold-formed steel sections subjected to web crippling have been published with the aim to improve and extend the applicability of the empiric equations given in the above mentioned design standards with a focus on channel sections [31-36], channel sections with perforations [37-40] as well as proprietary beams [41] and SupaCee sections [42]. With new emerging alloys available in construction and more advance methods of analysis, web crippling studies also exist on cold-formed high strength steel tubes [43], stainless steel [44-50] as well as aluminium alloys [51-53] among others. 
Although material and geometrical nonlinearities make predictive design equations based on first principles hard to obtain, efforts were made to derive analytical models for the treatment of web crippling [11, 14, 28, 54-61]. These studies were based on traditional yield line mechanisms that combined with experimental observations were used to define web crippling collapse mechanisms and post buckling behaviour upon which to derive analytical equations. Web crippling mechanisms including the rolling mechanism, the yield arc mechanism and the yield eye mechanism for instance were identified for hat sections [14] and subsequently used for multiple web profiles (i.e. sheeting profiles) [61]. Since late 2000s and beginning of 2010s the current trend in web crippling research is to shift from recalibrating empiric equations with test and numerical data to semi-empirical design approaches that combine numerical modelling and analytical methods [62,63]. There is also research underway to develop finite strip analysis for web crippling to ultimately predict the web crippling strength as a function of the cross-sectional slenderness primarily for channel sections [64-67].

Departing from empirical design approaches, a new slenderness-based design approach was proposed by Duarte and Silvestre [68] for the web crippling design of channel sections. The underpinning concept of this approach is that, as with other buckling modes, web crippling resistance decreases with increasing slenderness, hence a buckling reduction factor $\chi$ can be explicitly determined as a function of section slenderness $\bar{\lambda}$, which is defined by Eq. (1), where $R_{w, p l}$ is the plastic resistance load and $R_{w, c r}$ is the elastic critical buckling load. In this approach, the buckling reduction factor $\chi$ is determined by applying Eq. (2), where $R_{w}$ is the web crippling resistance. Eq. (2) can be expressed as a function of the slenderness and two dimensionless coefficients A and B. It was shown [68] that the semi-empiric slenderness-based design method provides reasonable predictions for the web crippling resistance, however, the proposed equations are limited to a small range of web slendernesses, corner radii and geometries. Subsequently, Bock and Real [69] adapted the slenderness-based design method to predict the web crippling resistance of cold-formed stainless steel hat sections and. In both articles, it was proved that a slendernessbased approach is possible for web crippling design whilst achieving more accurate and reliable predictions than existing design standards.

$\bar{\lambda}=\sqrt{\frac{R_{w, p l}}{R_{w, c r}}}$

$\chi=\frac{R_{w}}{R_{w, p l}}=\frac{A}{\bar{\lambda}^{B}}$

To the best knowledge of the authors and based on the pool of studies found in the literature, tests on sigma sections subjected to concentrated transverse loads have not been reported to date. This paper therefore reports the first experimental investigation on cold-formed sigma sections subjected to interior one flange (IOF) loading. The tests are used to develop a finite element (FE) model upon which to base parametric studies and the development of a slenderness based approach for web crippling design of sigma sections subjected to IOF loading.

\section{Experimental investigation}

\subsection{Specimens}

A series of tests were performed on sigma purlins subjected to a concentrated load parallel to their web. The tested specimens are cold- formed and have a nominal yield strength of $450 \mathrm{~N} / \mathrm{mm}^{2}$. Tensile coupon tests on flat coupons extracted from the web of the sections were conducted by the manufacturer and the obtained key material properties, including Young's modulus, yield strength, $1 \%$ proof strength, ultimate tensile stress and strain at fracture are reported in Table 1, where it can be observed that the actual yield strength is very close to the nominal one. Both material coupons exhibited a well-defined yield point followed by mild strain-hardening until the attainment of the ultimate tensile stress as shown in Fig 2. 
Table 1: Material properties from tensile coupon tests.

\begin{tabular}{cccccc}
\hline $\begin{array}{c}\mathrm{t} \\
(\mathrm{mm})\end{array}$ & $\mathrm{E}\left(\mathrm{N} / \mathrm{mm}^{2}\right)$ & $\begin{array}{c}\mathrm{f}_{\mathrm{y}} \\
\left(\mathrm{N} / \mathrm{mm}^{2}\right)\end{array}$ & $\begin{array}{c}\mathrm{f}_{1.0} \\
\left(\mathrm{~N} / \mathrm{mm}^{2}\right)\end{array}$ & $\begin{array}{c}\mathrm{f}_{\mathrm{u}} \\
\left(\mathrm{N} / \mathrm{mm}^{2}\right)\end{array}$ & $\begin{array}{c}\varepsilon_{\mathrm{f}} \\
(\%)\end{array}$ \\
\hline 1.2 & 193000 & 447 & 470 & 480 & 14.7 \\
2.47 & 206000 & 461 & 470 & 517 & 24.0 \\
\hline
\end{tabular}

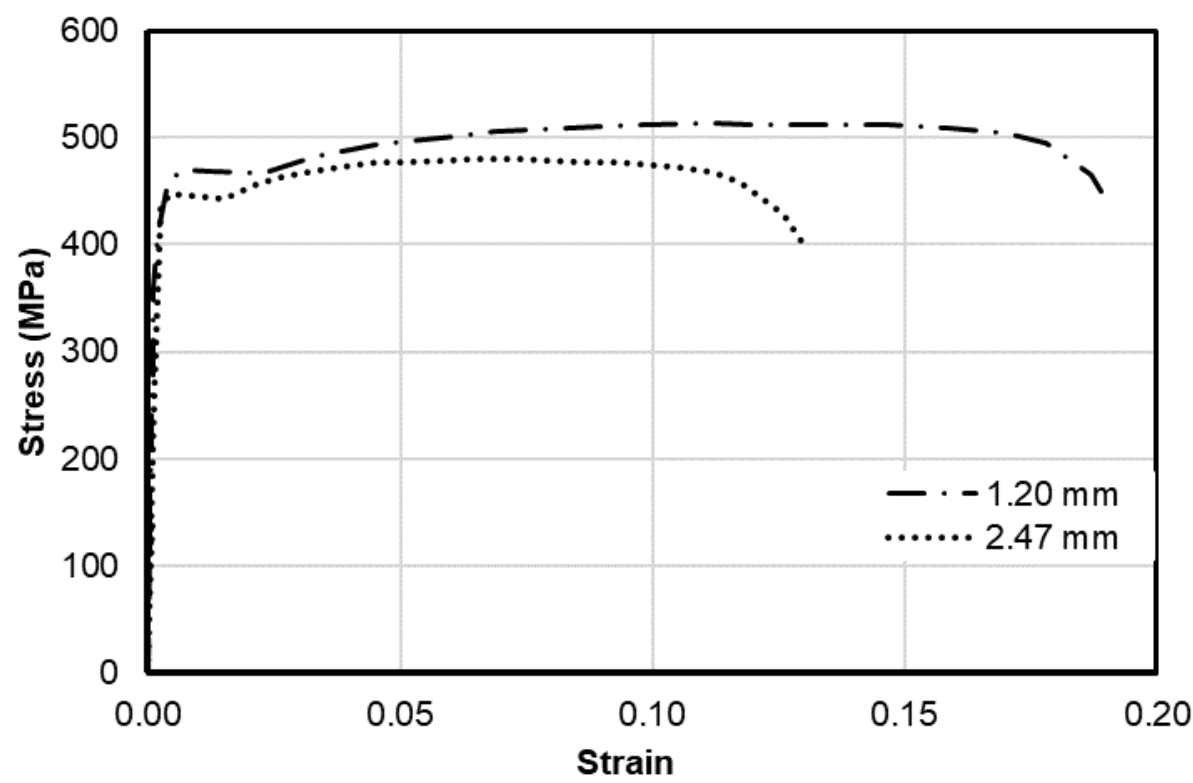

Fig. 2. Stress strain curves of material coupons

The minimum required lengths of the tested specimens were determined according to the requirements of the American Specification for cold-formed steel structures AISI S100-16 [19] which specify a minimum distance between the end of the bearing plate and the support equal to 1.5 times the overall depth of the web for tests corresponding to the IOF loading case. Since IOF will always be accompanied by a coexisting bending moment, the minimum distance specified in AISI S100-16 [19] was selected to minimise the effect of the bending moment on the web crippling strength of the tested specimens. An overhang of $75 \mathrm{~mm}$ was provided beyond the ends on either side of the specimen.

Two different section geometries were considered in the experimental studies. The chosen sections have nominal total web depths of 225 and $265 \mathrm{~mm}$, and nominal thicknesses of 1.2 and 2.5 respectively, thus resulting in two nominal web slenderness (total web depth/thickness) values 106 and 188. For each cross-section three different bearing plate widths $(\mathrm{N})$ namely, $50 \mathrm{~mm}, 75 \mathrm{~mm}$ and $100 \mathrm{~mm}$ were employed. Prior to testing, measurements of the geometry of each specimen were taken at three locations along their length using a digital vernier caliper for the flat parts of the sections and a radius gauge for the corners; the results were averaged to obtain representative values. In Table 2, the measured cross-sectional dimensions of the cold-formed steel lipped sigma sections considered in the tests are reported, where $t$ is the thickness, $h$ is the total web depth, $h_{1}$ is the outer web depth, $h_{2}$ is the middle web depth, $d$ is lip depth, $r_{1}$ is the internal root radius at the flange-web and flange-lip junctions and $r_{2}$ the internal root radius at the outer web-middle web junctions. The specimens were labelled according to their nominal cross-sectional dimensions and employed bearing plate width, e.g. specimen " $22512-50$ " corresponds to a nominal total web depth of 225 $\mathrm{mm}$, a nominal thickness of $1.2 \mathrm{~mm}$, and the width of bearing plate of $50 \mathrm{~mm}$. Fig. 3 shows the definition of the symbols used to define cross-sectional dimensions. 
Table 2 Measured geometric dimensions of tested specimens

\begin{tabular}{ccccccccc}
\hline Specimen & $\begin{array}{c}\mathrm{h} \\
(\mathrm{mm})\end{array}$ & $\begin{array}{c}\mathrm{b} \\
(\mathrm{mm})\end{array}$ & $\begin{array}{c}\mathrm{h}_{1} \\
(\mathrm{~mm})\end{array}$ & $\begin{array}{c}\mathrm{h}_{2} \\
(\mathrm{~mm})\end{array}$ & $\begin{array}{c}\mathrm{t} \\
(\mathrm{mm})\end{array}$ & $\begin{array}{c}\mathrm{d} \\
(\mathrm{mm})\end{array}$ & $\begin{array}{c}\mathrm{r}_{1} \\
(\mathrm{~mm})\end{array}$ & $\begin{array}{c}\mathrm{r}_{2} \\
(\mathrm{~mm})\end{array}$ \\
\hline $22512-50$ & 227.1 & 61.9 & 51.6 & 121.1 & 1.19 & 19.01 & 4.5 & 5.5 \\
$22512-75$ & 226.8 & 62.3 & 51.1 & 121.8 & 1.20 & 19.07 & 4.5 & 5.5 \\
$22512-100$ & 227 & 61.8 & 51.6 & 121 & 1.20 & 18.90 & 4 & 5 \\
$26525-50$ & 265.3 & 63.6 & 64.3 & 133.9 & 2.49 & 20.31 & 4 & 5 \\
$26525-75$ & 265.4 & 63.6 & 64.8 & 133 & 2.47 & 20.28 & 4 & 5 \\
$26525-100$ & 265.4 & 63.6 & 64.8 & 133 & 2.47 & 20.28 & 4 & 5 \\
\hline
\end{tabular}

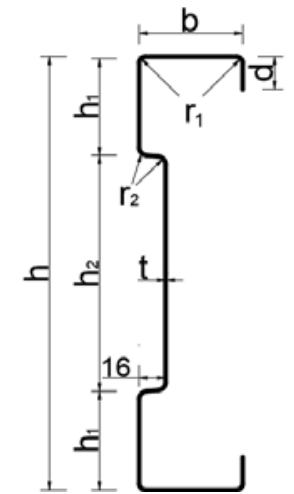

Fig. 3. Cross-section geometry and symbols

\subsection{Setup and instrumentation}

The sigma sections were tested under the interior-one-flange (IOF) loading condition specified in AISI S100-16 [19] as shown in Fig. 4a. As shown in Fig. 4b, angle cleats bolted to the specimen were used at the support locations in accordance with current practice to prevent failure of the end cross-sections. The angle cleats were also bolted to a bearing plate which was resting on half rollers to allow free rotation of the ends in the plane of loading and achieve pin ended conditions. Loading was applied on the top flange at mid-span through a bearing plate that was loaded by a hydraulic actuator. The connection of the specimen to the angle cleats at the supports provided adequate lateral and torsional support whilst the contact and friction between the loading plate and the actuator prevented any lateral displacement or rotation at the loading point. The adequacy of this set up was verified during testing where no evidence of lateral or torsional deformations where observed. The adoption of this set up was chosen as a better replication of loading conditions likely to occur in practice since purlins connected at regular intervals are not usually employed in practice. A load cell positioned such that its centroid coincided with the centroid of the actuator and with the web flange to web junction of the specimen was positioned between the actuator and the bearing plate. Since the only available degree of freedom of the actuator was the vertical displacement and due to the continuous contact of the actuator with the load cell and of the load cell with the bearing plate, all rotations of the bearing plate were effectively restrained. The width of the bearing plate was varied as part of the experimental investigation. 


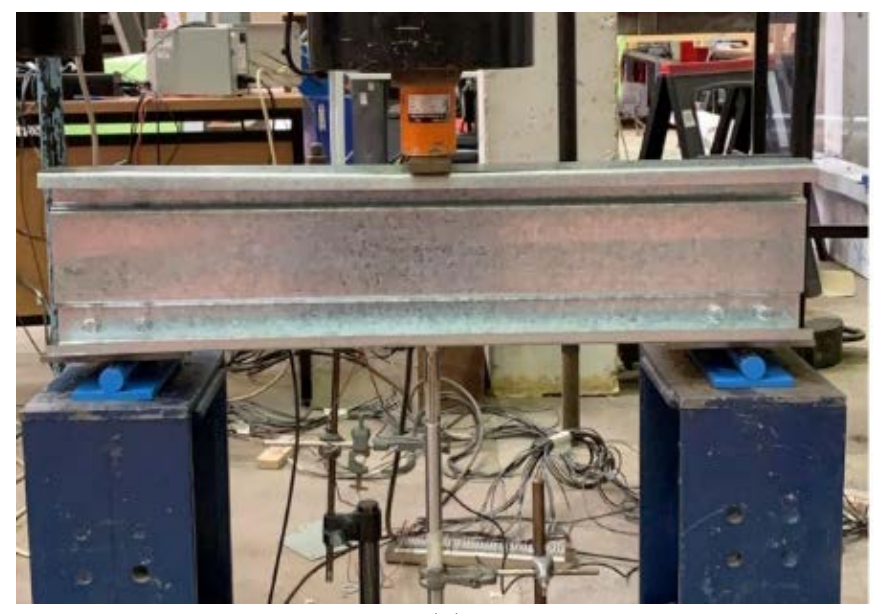

(a)

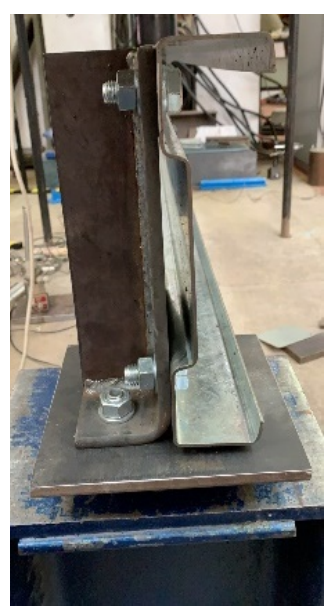

(b)

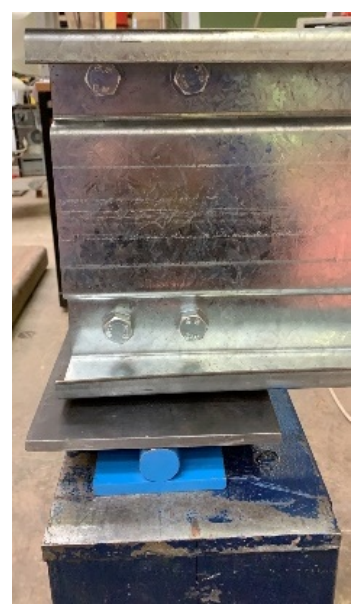

Fig. 4. web crippling test set up

All test specimens were first loaded up to $2 \mathrm{KN}$ and kept for 1 minute to attain a complete contact between the actuator and the bearing plate, and to check that everything was working as expected. Afterwards, the load was continuously applied until the ultimate load reached and specimens failed. The employed loading rate was $1.6 \mathrm{~mm} / \mathrm{min}$.

The employed instrumentation included a load cell to measure the applied force, which was positioned between the bearing plate and the hydraulic actuator, and three linear vertical displacement transducers (LVDTs), which were used to measure the vertical displacements at three points along the depth of the specimens' mid-section. These three points were the top flange $\mathrm{LVDT}_{1}$, the bottom flange $\mathrm{LVDT}_{2}$ and the bottom of the upper outer web $\mathrm{LVDT}_{3}$ (i.e. the upper horizontal web folding). The utilisation of several LVDTs along the depth of the section allowed the quantification of the web-crippling deformation of the upper and middle web and thus the identification of distinct failure modes. To determine the web-crippling deformation of the upper outer web, the readings from $\mathrm{LVDT}_{3}$ were subtracted from the readings from $\mathrm{LVDT}_{1}$, while the web crippling deformation of middle web was determined subtracting the $\mathrm{LVDT}_{3}$ readings from the readings from $\mathrm{LVDT}_{2}$. All instrumentation was connected to a data acquisition system that logged data every second.

\subsection{Test Results}

The experimentally obtained ultimate load for all tests is reported in Table 3 together with the observed failure mode for each tested specimen. As expected, all specimens failed by web crippling, albeit the corresponding deformation patterns differed. It is noted that there were no signs of bearing failure at web holes since the applied forces were much smaller than the design bearing strength of the cleat/specimen connection. For the more slender sections, web crippling deformations were contained only within the upper web and the top part of the middle web, whilst for the thicker sections, deformations were spread throughout the whole upper and middle web with exception of specimen 26525-50 where web crippling occurred only within the upper web, as illustrated in Figs. 5-7. During the test, the upper outer web deformation of the thinner sections continuously increased until the maximum capacity was reached, whilst for the thicker sections the upper outer web crippled initially and twisted thereafter as shown in Fig. 6(b). Following the distinction between yield-arc mechanism and rolling mechanism discussed in [14], all slender (i.e. $1.2 \mathrm{~mm}$ thick) sections exhibited a rolling mechanism, as can be seen in Fig.5, where the flange can be observed to remain horizontal as the corner radius rolls down through the web. All thick ( $2.5 \mathrm{~mm}$ thick) sections developed a mixture of a yield arc mechanism followed by a rolling mechanism, as can be clearly observed in Fig 6, where the flange rotates with increasing loading. 

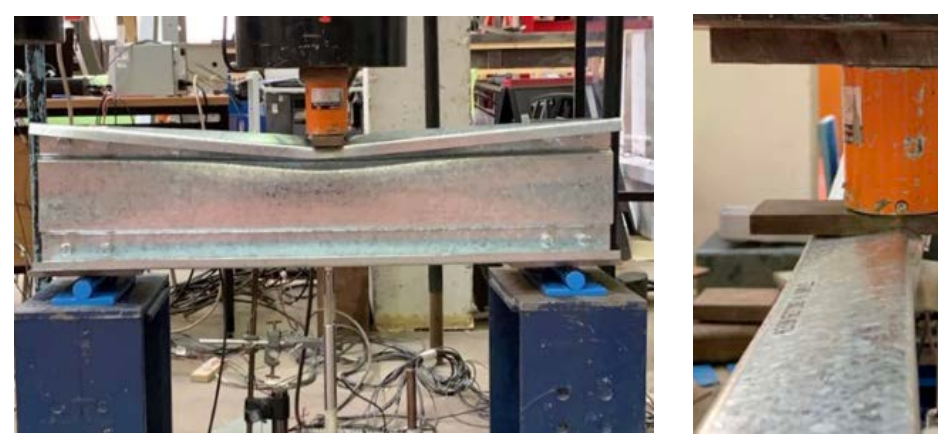

Fig. 5. Failure mode of specimen 22512-50

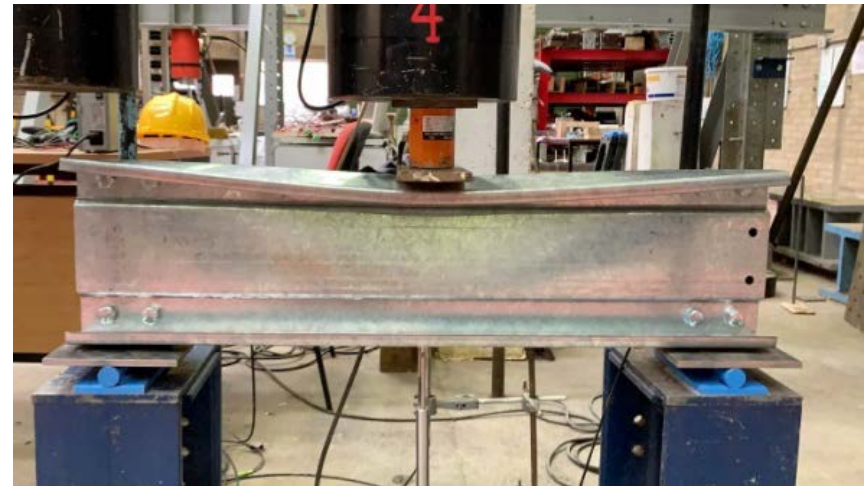

(a)

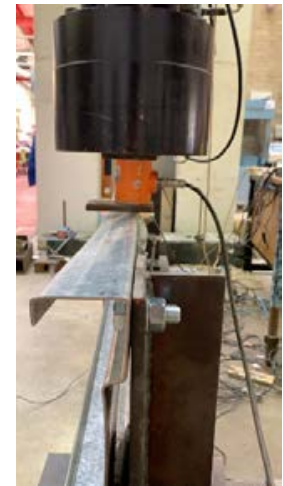

(b)

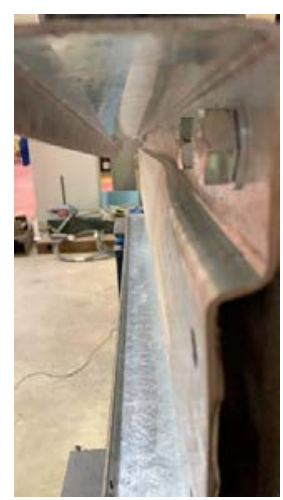

b)

Fig. 6. Web crippling at the whole upper and middle web (a) followed by upper web twist (b) (26525-100)
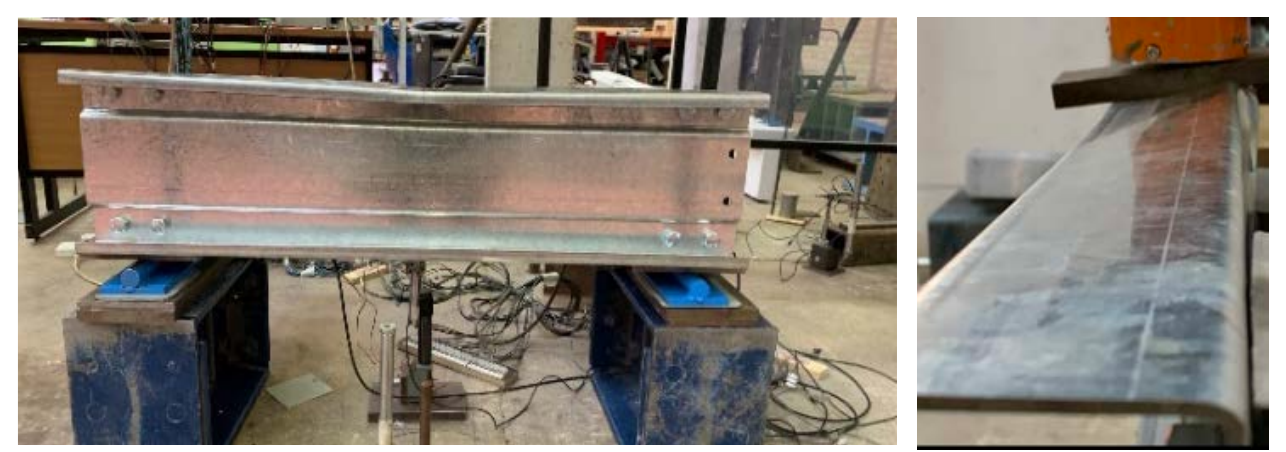

Fig. 7. Web crippling of the upper web of specimen 26525-50

Table 3 Summary of experimental results

\begin{tabular}{|c|c|c|}
\hline Specimen & $R_{w, E x p}$ & Failure mode \\
\hline $22512-50$ & 9.47 & Web crippling of the upper web and the top part of the middle web \\
\hline 22512-75 & 9.20 & Web crippling of the upper web and the top part of the middle web \\
\hline $22512-100$ & 9.01 & Web crippling of the upper web and the top part of the middle web \\
\hline $26525-50$ & 30.49 & Web crippling of the upper web only \\
\hline $26525-75$ & 33.87 & $\begin{array}{c}\text { Web crippling of the upper and whole middle web followed by twisting of the } \\
\text { upper web }\end{array}$ \\
\hline 26525-100 & 36.00 & $\begin{array}{c}\text { Web crippling of the upper and whole middle web followed by twisting of the } \\
\text { upper web }\end{array}$ \\
\hline
\end{tabular}

The applied transverse load is plotted against the three displacements measured by the three LVDTs in Fig. 8 where the top, mid and bottom deflection corresponds to the readings from LVDT 1 , LVDT3 and $\mathrm{LVDT}_{2}$, respectively. In this figure It can be seen that both tested specimens display similar response where the top and middle deformations are large in comparison with bottom one. The two distinct failure modes observed for the tested sections are also associated with qualitatively different 
load deformation responses. The more slender sections display an initially linear response followed by a secondary linear region of reduced stiffness, within which the deformations of the top part of the section increase faster than those of the upper part of the middle web thus indicating that crippling deformations are primarily combined within the upper web. The gradual transition from the initial to the secondary linear part of the response is accompanied by significant plastic deformations and the stable nature of this secondary curve demonstrates the ability of the section to redistribute the stresses internally and accommodate increased load. This behaviour is consistent with a rolling mechanism [14]. On the contrary, the stockier sections display a linear response which gradually degrades until the maximum load corresponding to web crippling of the upper web is reached, whereupon the load bearing capacity is lost and the load decreases gradually. The gradual decrease in load is consistent with a section failing by a combination of a yield arc and a rolling mechanism, as pure yield arc type of failure results in a more abrupt loss of strength upon the attainment of the ultimate load, whilst, as previously discussed, a rolling mechanism results in a response with two distinct linear regions prior to the attainment of the ultimate load.

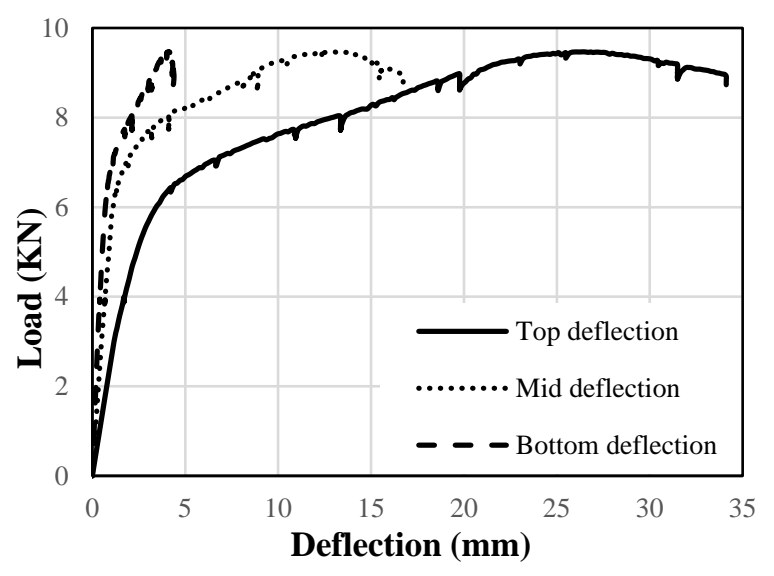

(a)

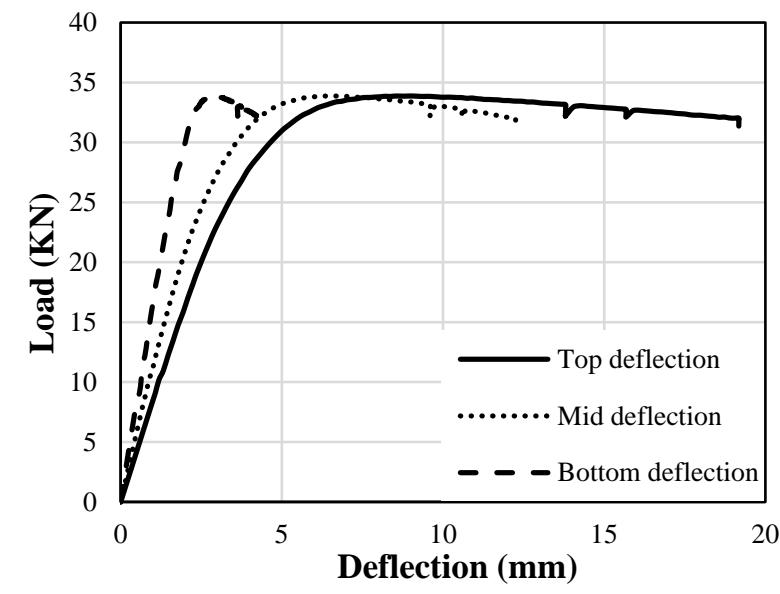

(b)

Fig. 8. Load-deformation response of specimens (a) 22512-50 and (b) 26525-75

Employing wider bearing plates was expected to increase the resistance area under the load application, hence to lead to higher web crippling capacities as observed in the thicker sections. However, this was not the case in the thinner sections where slightly larger web crippling loads were obtained by the smallest bearing plate width. Similar results have been previously observed in [42]. This can be attributed to the variations of initial imperfection levels and experimental scatter; the numerical models displayed the expected response as discussed hereafter.

\section{Numerical modelling}

In order to investigate further the structural behaviour of sigma sections subjected to IOF, an FE model was developed using ABAQUS [70] and validated against the reported test results. It was thereafter utilised to conduct parametric studies and generate additional data.

\subsection{Modelling assumptions}

A nonlinear static analysis was conducted to simulate the response of the specimens accounting for material and geometric nonlinearities as well as for the contact interaction between the specimen and the bearing plate. The curved corner of the cross-sections means that the load is applied eccentrically to web. Hence there was no need to perturb the idealized geometry to trigger web crippling as the magnitude of the initial geometric imperfections would have been significantly smaller than the $2^{\text {nd }}$ order effect caused by the eccentric application of the load. Therefore, no initial geometric imperfections were incorporated in the numerical models. The employed analysis type was general static and displacement control was utilized to apply the load and obtain the postultimate response. 
Corner strength enhancements and bending residual stresses are present in cold-formed steel sections due to the press-braking process and affect their structural response. The residual stresses lead to earlier yielding and hence reduced stiffness in some parts of the section thus increasing the susceptibility of the sections to buckling-related failure modes and reducing the strength of sections of intermediate slenderness. Conversely, the strength enhancements of the corner regions allow the press-braked corners to reach higher yield stresses compared to the flat plated elements of the sections, thus increasing the strength of sections particularly in the stocky slenderness region. Although predictive models for the determination of the magnitude and distribution of residual stresses and strength enhancements exist, they tend to display a relatively high scatter. Given that the two phenomena counteract each other (i.e. the strength enhancements increase the resistance and the residual stresses tend to reduce it), in accordance with past observations [44] neither residual stresses nor corner strength enhancements were incorporated in the model.

The linear four-nodded shell element with reduced the integration S4R was used to discretise the midline dimensions of the tested cold-formed steel sigma sections, as determined from the measured geometry reported in Table 2 . The SR4 element has been shown in past studies to give accurate results when modelling cold-formed sections subjected to web crippling [43,45,46,49,71,72]. As in the tests, three bearing plate widths were employed to load each section and an analytical rigid plate was used to simulate them and facilitate the load application on the sections. In accordance with the material properties reported in Table 1 , an elastic perfectly plastic material was assumed in the modelling with a Young's modulus E=200 GPa, a Poisson's ratio v=0.3 and a yield stress $f_{y}=450$ $\mathrm{MPa}$. As the material coupons exhibited a well-defined yield plateau and given the minimal strainhardening observed, no hardening was assumed for the material.

Achieving a balance between accuracy and computational efficiency requires employing a suitable mesh size, usually determined via a mesh convergence study. An element size of $10 \mathrm{~mm}$ was used for all flat parts of the sigma sections except for the top lip of the section where two elements were used in all models. The geometry of the curved corner at the flange to upper web junction has a profound influence on the structural behaviour of sections subjected to IOF. With increasing loading, the loaded flange rotates and the line of contact between the bearing plate and the specimen moves along the curved corner region towards the section's web. Furthermore, due to the progressive yielding of the integration points of the curve region, the yield lines also move along the curved region. Hence, due to the changing contact conditions between the specimen and the bearing plate and the movement of the yield lines over the curved corner region, a sufficiently fine mesh is required to discretise the curved corners. The appropriate mesh density in the corner regions was assessed through a separate mesh convergence study and the effect of adopting five different mesh size for the upper curved corner region at the flange to web junction was investigated. Fig. 9 shows the obtained load deformation response for each of the element number variations considered in the corner region. Clearly significant oscillations of the load-deflection response are exhibited when a small number of elements is employed, because of the effect of the mesh density on the contact with the bearing plate. It can be clearly observed that when 3 elements are used to discretise the corner region, there are three local maxima in the load deflection curve, as extensive yielding of the corner region leads to a drop in strength until the adjacent corner element comes in contact with the plate, thus decreasing the eccentricity of the applied load and allowing higher loads to be carried. The more the employed elements, the smoother the load transfer from the plate to the web of the section and the more accurately the development of the yield lines is captured, hence the smaller the apparent oscillations in the load-deflection curve. It is recommended herein that the top corners should be discretised by at least 15 elements to obtain a smooth response and sufficiently accurate results. All other corners were discretised using 3 elements. A typical mesh utilised in this study is illustrated in Fig. 10. 


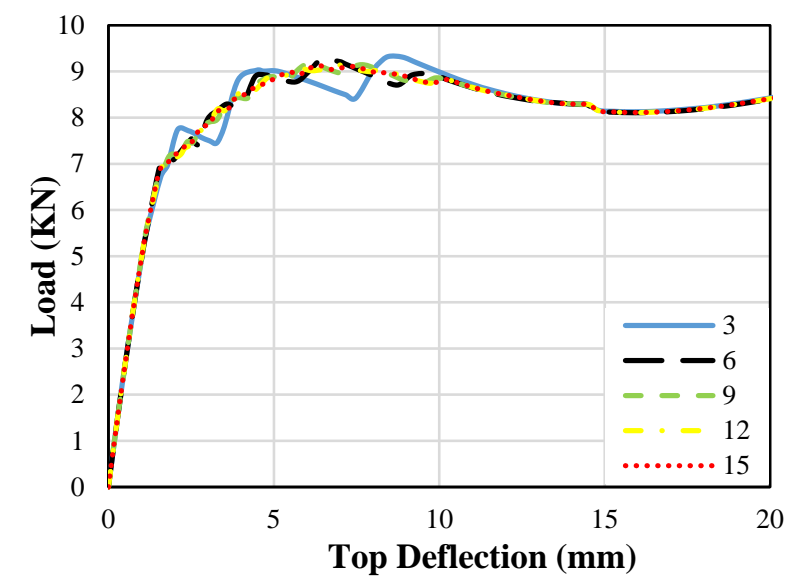

Fig. 9. Effect of corner region discretisation on obtained response

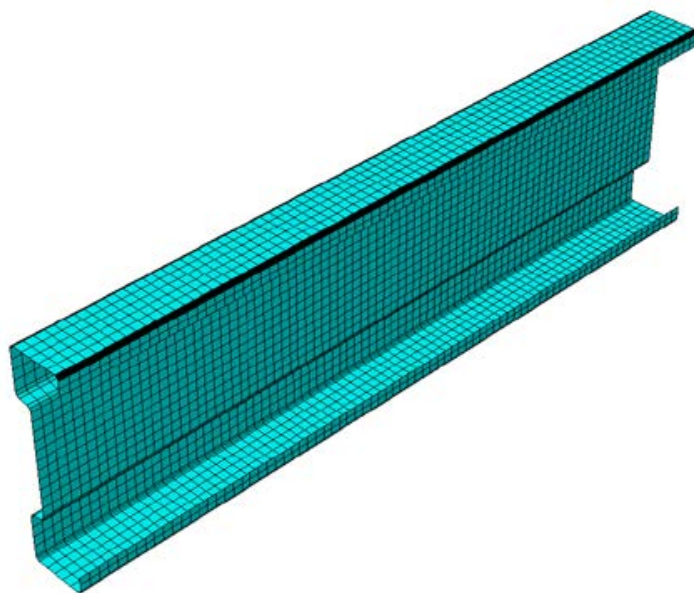

Fig. 10. Employed mesh size

An analytical rigid surface was used to simulate the bearing plate used in the tests and displacement control was used to load the model. The degrees of freedom of the analytical surface, defined at its reference point, were restrained except for the translation in the y-direction (i.e. parallel to the section web). To simulate the effect of the angle cleats and eliminate localised failure at the supports, kinematic coupling was utilised to tie the degrees of freedom along the web of the specimens at mid width of the angle cleats to the degrees of freedom of the constrained reference point to which boundary conditions were assigned as shown in Fig. 11. It is noted that rotations about both y and $\mathrm{z}$ axes and translations in the $\mathrm{y}$ and $\mathrm{x}$ directions were restrained at both supports, whilst the translation along the specimen axis (z-axis) and the rotation about the x-axis (in the plane of loading) were free at both ends.

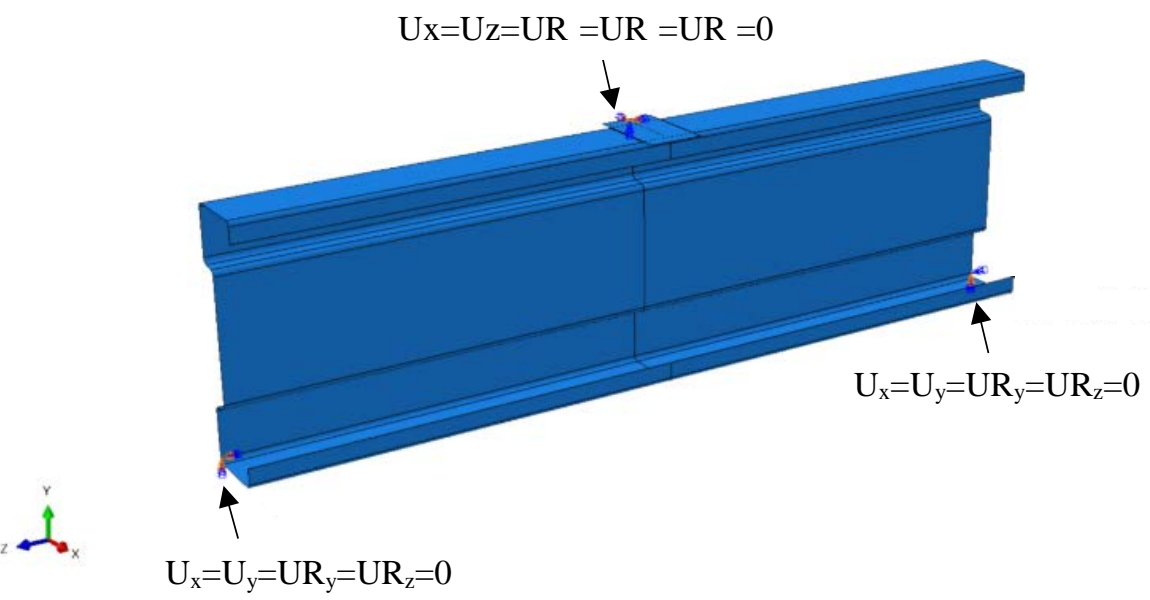

Fig. 11. Applied boundary conditions at the reference points controlling the degrees of freedom of the end cross-sections and the loading plate. 
The interaction between the sigma sections and bearing plates was simulated using contact pairs (surface-to-surface contact). The bottom surface of the bearing plates was defined as the master surface whilst, the top surface of the compression flange of the specimen and corner elements along with the flange were assigned as the slave surface, as they employed a finer mesh. The corner regions were included in the slave contact surface because they experience significant deformations and do eventually come in contact with the bearing plate at high localised deformations. Hard contact was assumed in the normal behaviour and the friction penalty contact with a friction coefficient of 0.2 was employed for the tangential behaviour.

\subsection{Validation}

Table 4 reports the comparison between the web crippling capacities obtained from the numerical analysis and the experiments, whilst a typical comparison of experimental and numerical loaddeflection response is shown in Fig. 12. The numerical failure modes were in good agreement with the experimentally observed failure modes as shown in Fig. 13. Overall, the numerical results show a reasonably good agreement with the experimental results with a mean $R_{w, E x p} / R_{w, F E}$ ratio of 0.96 and a coefficient of variation (COV) of 0.08 . From Table 4 it can be seen that larger differences between numerical and experimental results were observed for specimens 22512-100 and 26525100. This is believed to be due to the use of wider plates. Wide plates can be less flat than narrower plates and moreover the contact with the specimens take place over a longer specimen length where geometric imperfections may be more pronounced. The inconsistency between the initial stiffness of the tests and the numerical models has been previously observed by other researchers $[30,42,69,71]$ and is attributed to the sensitivity of the numerical model to initial imperfections and boundary conditions [69]. From the comparisons of the experimental and numerical results in terms of web crippling capacity, the failure mode and load-defection response, it can be concluded that the model is capable of replicating the main features of cold-formed steel lipped sigma sections behaviour failing by web crippling and is hence used in subsequent parametric studies.

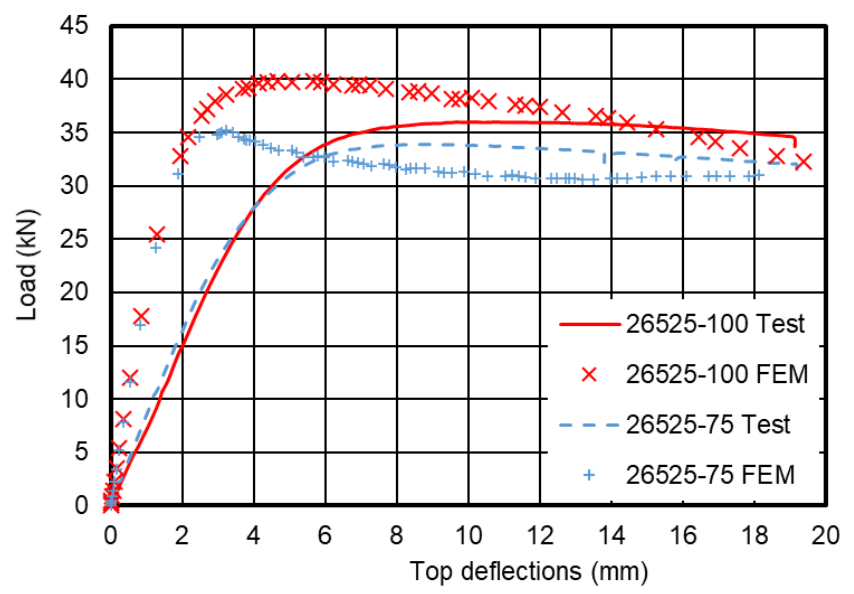

Fig. 12. Load-top web deformation response for sigma section 26525.

Table 4 Comparison of the experimental and numerical web crippling loads

\begin{tabular}{ccccc}
\hline Specimen & $\mathrm{N}(\mathrm{mm})$ & $R_{w, E x p}(\mathrm{KN})$ & $R_{w, F E}(\mathrm{KN})$ & $R_{w, E x p} / R_{w, F E}$ \\
\hline $22512-50$ & 50 & 9.47 & 9.13 & 1.04 \\
$22512-75$ & 75 & 9.20 & 9.45 & 0.97 \\
$22512-100$ & 100 & 9.01 & 10.84 & 0.83 \\
$26525-50$ & 50 & 30.49 & 29.88 & 1.02 \\
$26525-75$ & 75 & 33.87 & 35.21 & 0.96 \\
$26525-100$ & 100 & 36.00 & 39.89 & 0.90 \\
\hline \multicolumn{5}{c}{ Mean } \\
\hline
\end{tabular}



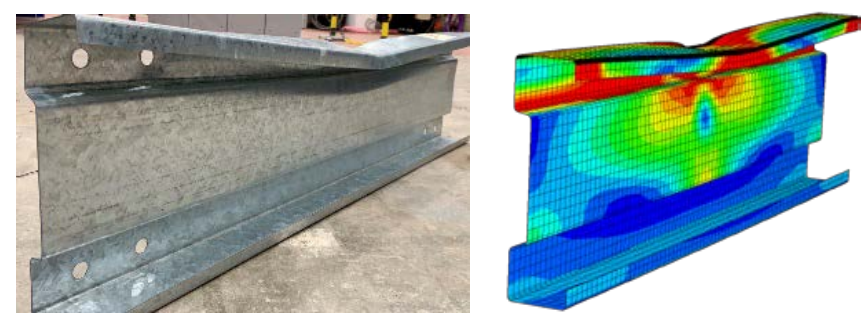

(a) $22512-75$
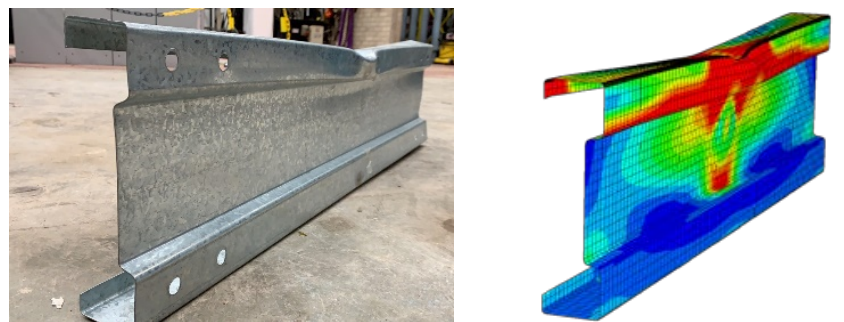

(b) 22512-50
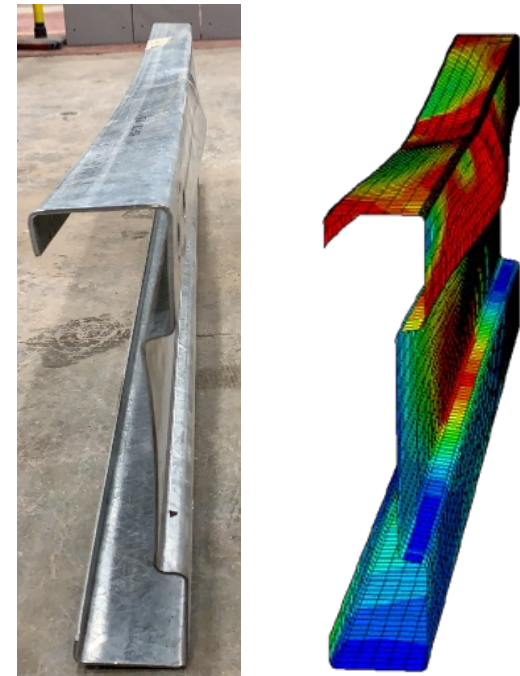

(c) $26525-100$

Fig. 13. Comparison of failure from experiments and numerical models

\section{Parametric study}

\subsection{Modelled geometries}

Following successful replication of the experimental observations, a comprehensive parametric study was performed, and several sigma sections were numerically tested. The parametric study consisted of sixty-three sigma section geometries, having web depths ranged from 200 to $300 \mathrm{~mm}$, the thickness ranged from 1.2 to $3 \mathrm{~mm}$, and three middle to total web depth ratios $\left(\mathrm{h}_{2} / \mathrm{h}\right): 0.4,0.6$ and 0.8. For all section, the lip depth (d), the internal root radius at the flange-web and flange-lip junctions ( $\left.\mathrm{r}_{1}\right)$ and the internal root radius at the outer web-middle web junctions ( $\left.\mathrm{r}_{2}\right)$ were fixed at $20 \mathrm{~mm}, 4 \mathrm{~mm}$ and $5 \mathrm{~mm}$ respectively. It should be highlighted that cross-section with middle to total web depth ratio of 0.6 represent existing sigma sections, whilst the other middle to total web depth ratios were considered to examine their influence in web crippling behaviour and evaluate the applicability of the slenderness- based design approach to a wide range of cross-section geometries likely to be employed in the future. The cross-section dimensions for all sections are summarised in Table 5. Similar to the tests, three bearing plate widths: 50, 75 and $100 \mathrm{~mm}$ were employed for each cross-section. In the parametric study, the lengths of the specimens are determined according to the American Specification [19] as the minimum length required for IOF loading conditions. The material adopted in the validation was utilised in the parametric study with $\mathrm{E}=200 \mathrm{GPa}, \mathrm{v}=0.3$ and $f_{y}=450 \mathrm{MPa}$.

Table 5. Summary of section geometries employed in the parametric study

\begin{tabular}{ccccccccc}
\hline Specimen & $\mathrm{h}(\mathrm{mm})$ & $\mathrm{b}(\mathrm{mm})$ & $\mathrm{h} 1(\mathrm{~mm})$ & $\mathrm{t}(\mathrm{mm})$ & $\mathrm{d}(\mathrm{mm})$ & $\mathrm{r} 1(\mathrm{~mm})$ & $\mathrm{r} 2(\mathrm{~mm})$ & $\mathrm{L}(\mathrm{mm})$ \\
\hline ASB200 & 200 & 62.5 & $20,45,60$ & $1.2,1.4,1.6,2,2.5$ & 20 & 4 & 5 & 700 \\
ASB225 & 225 & 62.5 & $23,45,68$ & $1.2,1.4,1.6,2,2.5$ & 20 & 4 & 5 & 800 \\
ASB240 & 240 & 62.5 & $24,50,72$ & $1.5,1.8,2.3,2.8$ & 20 & 4 & 5 & 820 \\
ASB265 & 265 & 62.5 & $27,60,80$ & $1.5,1.8,2.3,2.8$ & 20 & 4 & 5 & 900 \\
ASB300 & 300 & 75 & $30,60,90$ & $1.8,2.5,3$ & 20 & 4 & 5 & 1000 \\
\hline
\end{tabular}

\subsection{Analysis}

Three types of analysis were conducted in this parametric study: (a) eigenvalue analysis to obtain the critical buckling load $R_{w, c r}$, (b) first-order plastic analysis considering elastic-perfectly plastic material and no geometrical nonlinearities to obtain the plastic load $R_{w, p l}$ and (c) geometrically and materially nonlinear analysis to obtain the web crippling resistance $R_{w}$. The elastic critical buckling load and the plastic load are required to define the slenderness of the modelled sections, since, it has 
been shown [68,69], that there is a strong correlation between slenderness and web crippling resistance $R_{w}$. It has to be noted that the critical buckling load $R_{w, c r}$ and plastic load can only be obtained numerically $R_{w, p l}$ whilst, the web crippling load can be determined numerically and experimentally. All numerical results obtained from the three analyses are utilized hereafter to derive suitable predictive equations.

\subsubsection{Elastic critical buckling $\boldsymbol{R}_{w, c r}$}

From the eigenvalue analysis, the lowest elastic buckling load pertinent to web buckling was obtained as the critical buckling load of lipped sigma sections. Since contact interaction cannot be used in the eigenvalue elastic analysis in Abaqus, the interaction between the specimen and the bearing plate at midspan was simulated with kinematic coupling. All degrees of freedom of the nodes at the interface between the flat part of the flange closer to the web and bend radius along a width equals to the bearing plate width were constrained to a reference point as shown in Fig. 14 . This approach provided a good representation of the pertinent web crippling mode shape as shown in Fig. 15. The modelling of the supports was not changed in the elastic buckling analysis.

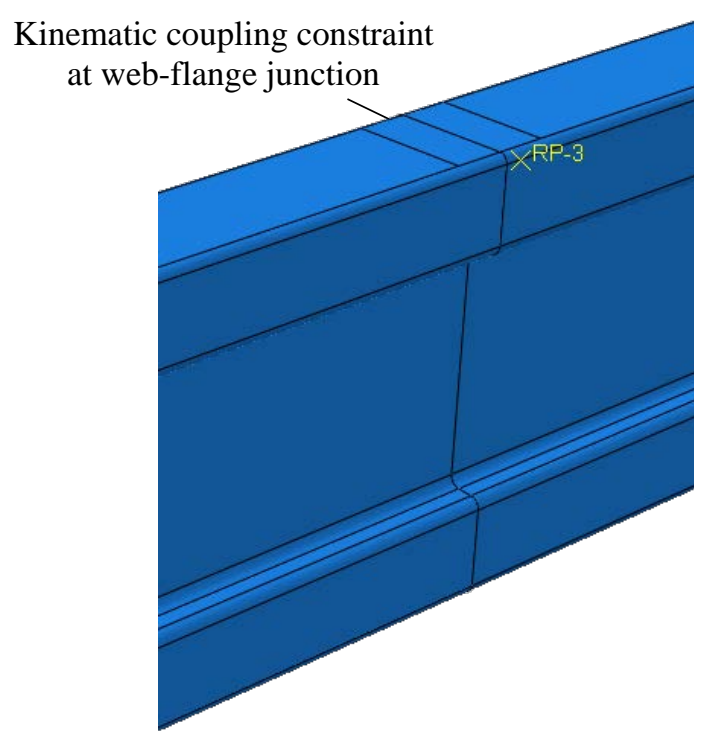

Fig. 14. Detail of the employed load application strategy for the elastic critical buckling analysis

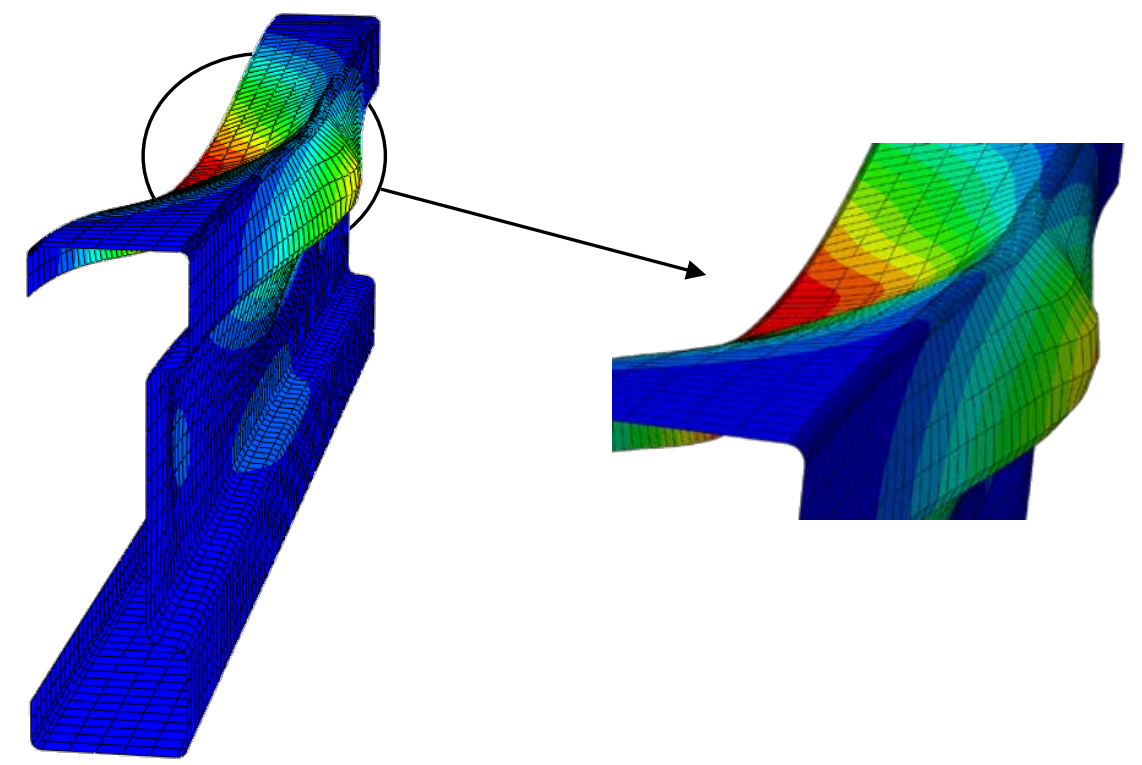

Fig. 15. Buckling mode shape corresponding to the elastic critical buckling load for web crippling $R_{w, c r}$ 


\subsubsection{Plastic load $R_{w, p l}$}

Apart from considering geometrical nonlinearities, all modelling assumptions adopted in previous validations were used in first-order plastic analysis to obtain the plastic buckling load. Determining the plastic load from the first-order plastic analysis was complex due to three reasons [73]: (i) the load-deflection curves sometimes dropped after obtaining unrealistically high deformations; (ii) on some occasions the numerical analysis terminated without achieving a maximum load; and (iii) the models may not reach a well-defined maximum and the load-deflection curves may keep increasing albeit with an ever-reducing slope. From the first order plastic analysis results, the latter problem was mostly observed, as depicted in Fig 16. To overcome this problem and determine the plastic load $R_{w, p l}$ from the load-deformation response obtained numerically, a graphical method was used. Graphical methods are available in the literature such as the Southwell plot [74], the modified Southwell plot [75] the convergence indicator plot [76] and the tangent stiffness plot [14]. Research carried out by Dos Santos et al. [73] concluded that all the above methods provide similar estimations for the plastic load with similar calculation efforts and derived a new simplified method based on the tangent stiffness plot which. Dos Santos et al. [73] method was used herein to extract the plastic load $R_{w, p l}$ from. This approach relies on the variation of tangent stiffness of a structural member obtained from the slope of the load-deformation response. The tangent stiffness Ki for each increment can be determined as the change of the applied load over the change in deflection. Following this approach, the plastic load is assumed to be reached when the tangent stiffness is equal to $1 \%$ of the initial stiffness. The plastic loads obtained by applying this technique are assumed to be the plastic loads of the sections and are utilised subsequently to derive a design method for the determination of the strength of sigma sections subjected to IOF.

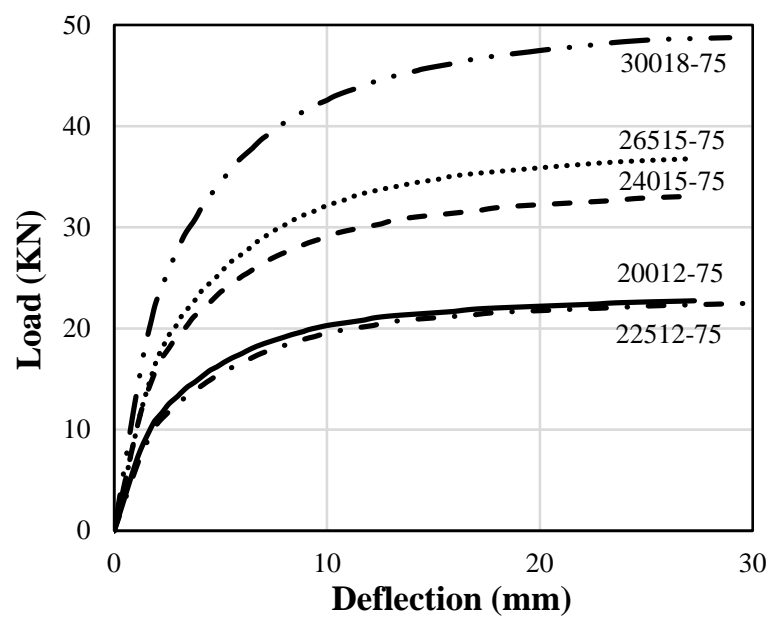

Fig. 16. load-deformation response obtained from the first-order analysis

\subsection{Comparison with NAS S100-16 [19] design proposal by Sundararajah et al} [42]

The north American specifications NAS S100-16 [19] specifies the unified empirical equation given in Eq. (3) to determine web crippling capacity of different cross-sections for all four loading condition. In Eq. (3) $h_{w}$ is the flat web height, $\theta$ is the angle between web and bearing surfaceand $C, C_{r}, C_{N}$ and $C_{w}$ are dimensionless coefficients related to the cross-section shape, internal radius, bearing length and web slenderness, respectively. According to NAS S100-16 [19]. The applicability limits of Eq. (3) are: $h_{w} / t \leq 200, N / t \leq 210, N / h_{w} \leq 2$ and $\theta=90^{\circ}$.

$R_{w}=C t^{2} f_{y} \sin \theta\left(1-C_{r} \sqrt{\frac{r}{t}}\right)\left(1+C_{N} \sqrt{\frac{N}{t}}\right)\left(1-C_{w} \sqrt{\frac{h_{w}}{t}}\right)$ 
As it is in the NAS S100-16 [19], Eq. (3) is not applicable to sections having stiffened webs such as sigma sections. Sundararajah et al. [42] conducted experimental and numerical investigations on SupaCee sections, which are C-sections with four web stiffeners, under IOF and EOF loading conditions to assess the applicability of Eq. (3). They compared experimental and numerical data against the NAS S100-16 predictions and found a reasonably good agreement. Sundararajah et al. [42] also proposed a new set of dimensionless coefficients for SupaCee sections, shown in Table 6. The applicability of the dimensionless coefficients given in the NAS S100-16 [19] and those proposed by Sundararajah et al. [42] for SupaCee sections to Sigma sections is assessed herein. The accuracy of the predictions can be seen in Table 7 where it is observed that the predictions from the NAS S100-16 [19] overestimate web crippling capacities (i.e mean ratio greater than 1), whilst reasonably good predictions are achieved by Sundararajah et al. [42] recalibrated proposal though the scatter is relatively high.

Table 6. web crippling coefficients

\begin{tabular}{ccccc}
\hline Proposed by & $C$ & $C_{r}$ & $C_{N}$ & $C_{w}$ \\
\hline NAS S100-16 [18] & 13 & 0.23 & 0.14 & 0.01 \\
Sundararajah et al [42] & 12.1 & 0.22 & 0.13 & 0.01 \\
\hline
\end{tabular}

Table 7. Comparison of experimental and numerical results with predicted web crippling loads

\begin{tabular}{cccccc}
\hline \multirow{2}{*}{$\begin{array}{c}\text { No.of tests: } 6 \\
\text { No. of FE models:189 }\end{array}$} & & \multicolumn{2}{c}{ Sundararajah et al [42] } \\
\cline { 2 - 3 } \cline { 5 - 6 } & $R_{w, \text { pred }} / R_{w, \text { EXP }}$ & $R_{w, \text { pred }} / R_{w, \text { EXP }}$ & & $R_{w, \text { pred }} / R_{w, \text { EXP }}$ & $R_{w, \text { pred }} / R_{w, \text { EXP }}$ \\
\hline Mean & 1.08 & 1.11 & & 0.99 & 1.02 \\
COV & 0.18 & 0.11 & & 0.17 & 0.11 \\
\hline
\end{tabular}

\section{Design recommendations}

\subsection{Proposed strength curve for sigma sections}

The obtained numerical results for the $R_{w, c r}$ and $R_{w, p l}$ loads are utilised to define the nondimensional slenderness $\bar{\lambda}$ of the simulated sections, whilst the obtained web crippling strength $R_{w}$ normalised by $R_{w, p l}$ defines the buckling reduction factor $\chi$. Plotting the buckling reduction factor against the non-dimensional slenderness, a strong correlation can be observed in Fig. 17. Hence, as for other buckling modes, the buckling reduction factor can be determined as a function of slenderness for sigma sections. Following a similar approach to that of [68] and [69] for channel sections and hat sections respectively, a strength curve for the web crippling resistance of sigma sections is proposed in Eq. (4) and depicted in Fig. 17. Note that Eq. (4) provides values for the coefficients A and B shown in Eq. (2) which were calibrated to best fit the numerical data.

$\chi=\frac{R_{w}}{R_{w, p l}}=\frac{0.37}{\bar{\lambda}^{0,71}}$

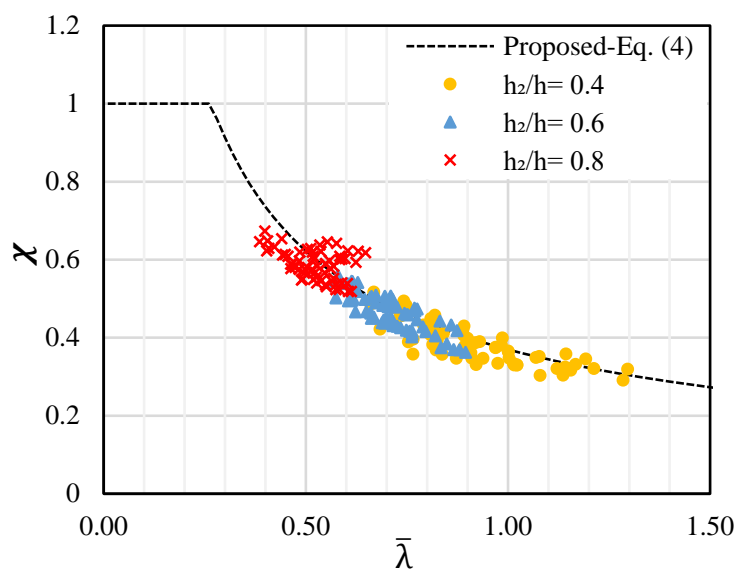

Fig. 17 FE results and strength curve for sigma sections 
It can be observed that, for the range of slenderness considered (i.e. 0.39 - 1.3), the proposed strength curve provides an excellent fit to the obtained results, whilst it follows a simple design framework similar to that adopted for other instability related failure modes. Key to the successful application of the design method based on strength curves is the prediction of the elastic critical buckling load $R_{w, c r}$ and the plastic load $R_{w, p l}$, as discussed hereafter.

\subsection{Predictive model for $\boldsymbol{R}_{w, p l}$}

Unlike the plastic resistance of a cross-section, the plastic resistance to web crippling $R_{w, p l}$ is not straightforward to obtain, however, several attempts have been conducted to predict the plastic resistance of web crippling theoretically [14,59]. Researchers have also developed analytical methods based on yield line mechanism [10,22,23,54,60,77]. While yield line mechanisms were adopted in Duarte and Silvestre [68] and Bock and Real [69], due to the complex cross-sectional geometry an empirical approach is adopted in this paper. Empirical approaches have also been found in the literature [78]. The empirical model presented in Eq. (5) is proposed for the prediction of the plastic web crippling resistance of Sigma sections subjected to IOF loading. The accuracy of the obtained predictions can be assessed in Fig. 18, where the predicted plastic resistances $R_{w, p l, p r e d}$ have been plotted against the numerical ones $R_{w, p l, F E}$. Overall, a reasonably good agreement between the predicted and the numerically obtained $R_{w, p l}$ is observed. The mean value of the predicted over the numerical $R_{w, p l}$ is 0.98 and the COV is 0.06 .

$R_{w, p l}=f_{y} \cdot \frac{3 t\left[N+2.5\left[\left(h_{1}-2 r_{1}\right)+2.5\left(t+r_{1}\right)\right]\right]}{16-2 t}$

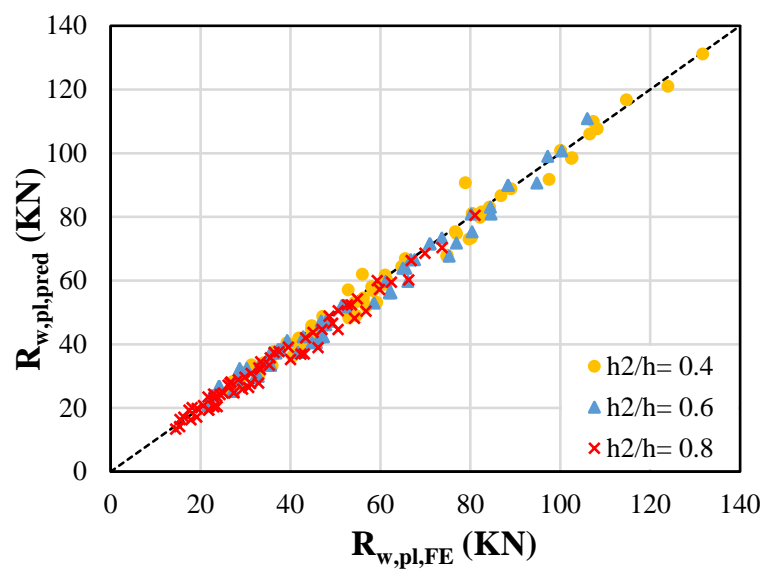

Fig. 18 Predicted vs FE values for the plastic web crippling load $R_{w, p l}$

\subsection{Predictive model for $\boldsymbol{R}_{w, c r}$}

To the best of the authors' knowledge there is no closed formed solution for the determination of the elastic critical buckling load for web crippling $R_{w, c r}$. It may be determined numerically using either the traditional finite element method as done in this paper or the constrained shell finite element method [79]. The suitability of similar empirical equations derived for lipped channel sections under IOF [36] has been assessed and it was concluded that the derivation of a new equation was required. The predictive model derived herein is based on the critical buckling load equation for plates subjected to in-plane loading given in Eq. (6), where $E$ is Young's modulus, $t$ is the thickness of the plate, $h$ is the width of the plate and $k_{f}$ is a buckling factor. For Sigma sections, $h$ was set equal to $h_{1}$ since the buckling mode shapes obtained from eigenvalue buckling analysis displayed very limited deformation of the middle and lower web, with the upper web experiencing most of the buckling deformations. 
$R_{w, c r}=k_{f} \cdot \frac{\pi^{2} E t^{3}}{12\left(1-v^{2}\right) h}$

A buckling factor $k_{f}$ was therefore derived through multi-regression analysis as successfully done in [68 and 69]. The main parameters considered in the multi-regression analysis included the section flange width over the upper web depth ratio $b / h_{1}$, the bearing width over the beam length ratio $N / L$, the overall depth over thickness ratio $h / t$, the ratio of the upper web depth over the overall section depth $h_{1} / h$ and the mean root radius over thickness ratio $\left(0.5 t+r_{1}\right) / t$. The derived buckling factor is presented in Eq. (7) while a graphical assessment is show in in Fig. 19, where the predicted buckling factor $k_{f, p r e d}$ have been plotted against the numerical ones $k_{f, F E}$. The overall mean value of the predicted over the numerical $R_{w, c r}$ is 0.98 and the COV is 0.14 .

$k_{f}=-0.78 \frac{b}{h_{1}}+11.62 \frac{N}{L}-0.006 \frac{h}{t}+0.87 \frac{h_{1}}{h}+1.59 \frac{r_{i}+0.5 t}{t}$

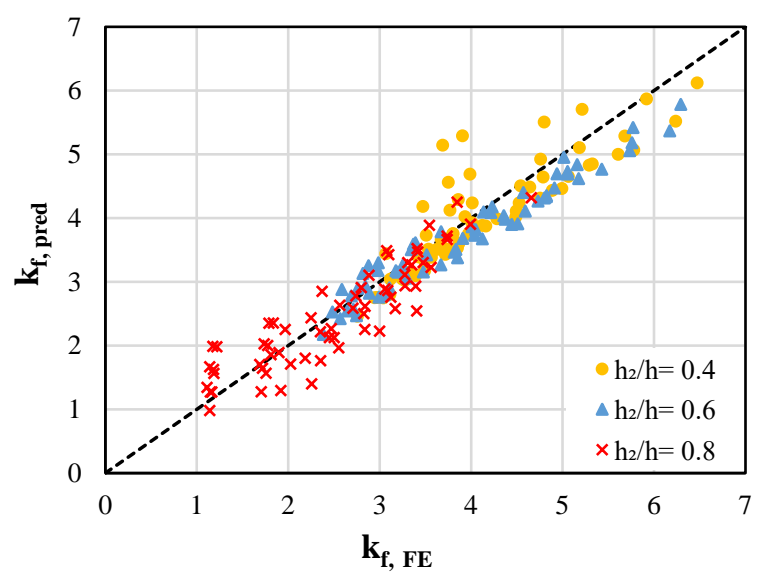

Fig. 19 Predicted vs FE values for buckling factor $k_{f}$ of the elastic critical web crippling load $R_{w, c r}$

\subsection{Assessment of the proposed method}

Using the predictive models presented in Equations (5)-(7) and the derived strength curve given in Eq. (4), the web crippling strength of Sigma sections subjected to IOF loading can be determined. The predicted web crippling strengths by the proposed method $R_{w, \text { pred }}$ are plotted against the numerical web crippling loads achieved by the full nonlinear models $R_{w, F E}$ in Fig. 20 where overall an excellent agreement can be observed with an average predicted over numerical web crippling strength of 1.00 and a COV of 0.07 . Table 8 reports a breakdown of the average predicted over numerical web crippling strength for different data sets.

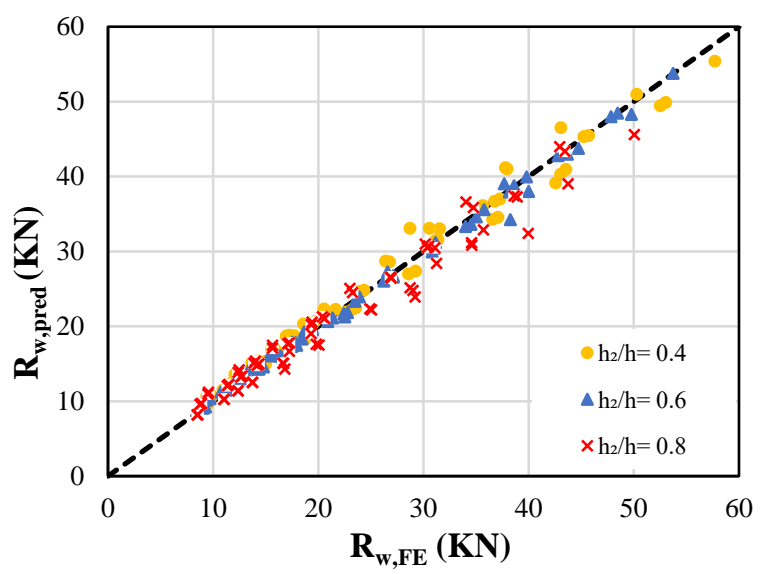

Fig. 20 Predicted vs FE values for the web crippling load $R_{w}$ of sigma sections 
Table 8. Assessment of design recommendations

\begin{tabular}{ccc}
\hline Web ratio & \multicolumn{2}{c}{$R_{w, \text { pred }} / R_{w, \text { EXP }}$} \\
\cline { 2 - 3 }$\left(\mathrm{h}_{2} / \mathrm{h}\right)$ & Mean & COV \\
\hline 0.4 & 1.03 & 0.06 \\
0.6 & 1.00 & 0.03 \\
0.8 & 0.98 & 0.09 \\
All & 1.00 & 0.07 \\
\hline
\end{tabular}

\section{Conclusions}

In this paper six experimental tests on sigma sections subjected IOF loading were reported. The experimental results were supplemented by extensive numerical modelling and, upon validation of the FE model, parametric studies were conducted to generate additional data considering a wide range of cross-section geometries and a slenderness ranging from 0.39 to 1.3 . The obtained results were used to extend a slenderness-based design approach previously developed for channel sections and hat sections $[68,69]$ to the design of sigma sections subjected to IOF. Empirical equations for the prediction of the plastic resistance and the elastic critical buckling load of sigma sections were reported and a new strength curve relating the slenderness to the web crippling reduction factor $\chi$ has been calibrated for sigma sections. The proposed method in Eqs. (4-7) gives excellent results within the range of parameters adopted for its calibration. An additional merit of the method beyond its accuracy is that it is conceptually harmonised with traditional design approaches for other buckling modes and that with advancements in numerical methods [28] the reliance on empirical equations tailored to specific cross-section shapes can be eliminated. The research presented in this paper corroborates yet again that slenderness based (or direct strength) approaches are possible for web crippling design. Further research is underway to verify the proposed design approach for sigma sections subjected to combined web crippling and bending moment and extend the slenderness based design approach to other cross-section shapes and materials.

\section{Acknowledgements}

The donation of specimens by Albion sections and the insight and advice offered by its technical director, Mr Thomas Hughes, is gratefully acknowledged. The first author would like to thank the Saudi Arabian Cultural Bureau for sponsoring his doctoral studies.

\section{References}

[1] Yu WW and LaBoube RA (2010) Cold-formed steel design. 4th ed., New York: John Wiley \& SonsInc.

[2] Winter G and Pian RHJ (1946) Crushing strength of thin steel webs. Engineering experiment station, Bulletin no. 35, Part 1. New York, USA.

[3] AISI 1968 Edition (1968) Specification for the design of cold-formed steel structural members. AISI 1968. Washington, DC: American Iron and Steel Institute.

[4] Beshara B and Schuster M (2000) Web crippling data and calibrations of cold-formed steel members. AISI Research Report RP00-2.2000 American Iron and Steel Institute; Washington,DC.

[5] Cain DE, LaBoube RA and Yu WW. The effect of flange restraint on web crippling strength of cold formed steel Z-and I-Sections. Final Report, Civil Engineering Study 95-3. Missouri, USA; 1995.

[6] Bhakta BH, LaBoube RA snd Yu WW. The effect of flange restraint on web crippling strength. Final Report, Civil Engineering Study 92-1. Missouri, USA; 1992.

[7] Winter G. 65th and 66th Progress reports on light gage steel beams of cold-formed steel. New York, USA; 1952 and 1953, respectively. Unpublished. 
[8] Hetrakul N and Yu WW (1978) Structural behaviour of beam webs subjected to web crippling and a combination of web crippling and bending. Civil Engineering Study 78-4, Final Rep., Univ. of Missouri-Rolla, Rolla, Missouri, USA.

[9] Langan JE, LaBoube RA snd Yu WW. Structural behavior of perforated web elements of coldformed steel flexural members subjected to web crippling and a combination of web crippling and bending. Final Report, Civil Engineering Study 94-3. Missouri, USA; 1994.

[10] Gerges RR. Web crippling of single web cold-formed steel members subjected to End OneFlange loading [MSc Project]. Canada: University of Waterloo; 1997.

[11] Young B and Hancock GJ (2001). Design of cold-formed channels subjected to web crippling. Journal of Structural Engineering (ASCE); 127:1137-44.

[12] Wing, BA. (1981) Web crippling and the interaction of bending and web crippling of unreinforced multi-web cold-formed steel sections [M.Sc.Project].Canada: University of Waterloo.

[13] Wu S, Yu WW and LaBoube RA (1997) Strength of flexural members using structural grade 80 of A653 Steel (web crippling tests). 3rd Progress Report, Civil Engineering Study 97-3. Missouri, USA.

[14] Bakker MCM and Stark JWB (1994). Theoretical and experimental research on web crippling of cold-formed flexural steel members. Thin-Walled Structures; 18:261-90.

[15] Baehre R (1975) Sheet metal panels for use in building construction-Recent research Projects in Sweden. In: Proceedings of the 3rd International specialty conference on cold-formed steel structures; Missouri, USA; 383-455.

[16] Yu WW (1981) Web crippling and combined web crippling and bending of steel decks. Structural Series, Civil Engineering Study 81-2. Missouri,USA.

[17] Studnicka J (1990) Web crippling of wide deck sections. In: 10th International specialty conference on cold-formed steel structures, Missouri, USA, 317-34.

[18] AISI 2002 Edition. Specification for the design of cold-formed steel structural members. AISI (2002). Washington, DC: American Iron and Steel Institute; 2002.

[19] AISI 16th ed. (2016) North American specification for the design of cold-formed steel structural members, S100-16th ed., Washington, D.C, U.S.A.

[20] EN 1993-1-3. Eurocode 3: Design of steel structures - Part 1-3: General rules - Supplementary rules for cold-formed members and sheeting. Brussels: European Committee for Standardization (CEN); 2006.

[21] Australian/New Zealand Standard (AS/NZS), Cold-Formed Steel Structures, AS/NZS 4600:2018, Standards Australia, Sydney, Australia, 2005.

[22] Zhao XL and Hancock GJ (1992) Square and rectangular hollow sections subjected to combined actions. Journal of Structural Engineering, 118, 648-68.

[23] Zhao XL and Hancock GJ (1995) Square and rectangular hollow sections under transverse endbearing force. Journal of Structural Engineering, 121, 1323-9.

[24] Santaputra C, Parks MB and Yu WW (1986). Web crippling strength of high strength steel beams. 8th International specialty conference on cold-formed steel structures; Missouri, USA.

[25] Sharp ML (1989). Behaviour of plates under partial edge loading. Proceedings of the Structures congress; 1989; San Francisco, USA: Steel Structures (ASCE).

[26] Sivakumaran K (1989). Analysis for web crippling behaviour of cold-formed steel members. Computers \& Structures; 32:707-19.

[27] Hofmeyer H, Kerstens JGM, Snijder HH and Bakker MCM (1999) Numerical and analytical modelling of hat-section web crippling behaviour, Acta Polytechnica, 39 (5), pp. 87-104.

[28] Hofmeyer H (2005). Cross-section crushing behaviour of hat-sections (Part I: Numerical modelling). Thin-Walled Structures; 43:1143-54.

[29] Ren WX, Fang SE and Young B (2006). Finite element simulation and design of cold-formed steel channels subjected to web crippling. Journal of Structural Engineering (ASCE); 132:16971975.

[30] Kaitilia O (2007) Web crippling of thin-walled cold formed steel cassettes. Journal of Constructional Steel Research, 63(6),766-778, 2007. 
[31] Gunalan S and Mahendran M (2015) Web crippling tests of cold-formed steel channels under two flange load cases. Journal of Constructional Steel Research 110, 1-15.

[32] Macdonald M, Don MAH, Kotelko M and Rhodes J (2011) Web crippling behaviour of thinwalled lipped channel beams. Thin-Walled Struct, 49 (5), pp. 682-690.

[33] Chen Y, Chen X and Wang C (2015) Experimental and finite element analysis research on cold-formed steel lipped channel beams under web crippling. Thin-Walled Structures, 87, 41-52.

[34] Sundararajah L, Mahendran M and Keerthan P (2016) Experimental studies of lipped channel beams subject to web crippling under two-flange load cases. Journal of Structural Engineering, 142(9):04016058.

[35] Janarthanan B, Mahendran M and Gunalan S (2019) Numerical modelling of web crippling failures in cold-formed steel unlipped channel sections. Journal of Constructional Steel Research. Vol. 158, pp. 486-501.

[36] Janarthanan B, Sundararajah L, Mahendran M, Keerthan P and Gunalan S (2019) Web crippling behaviour and design of cold-formed steel sections. Thin-Walled Structures. Vol. 140, pp. 387-403.

[37] Uzzaman A, Lim JBP, Nash D, Rhodes J and Young B (2012) Web crippling behaviour of cold-formed steel channel sections with offset web holes subjected to interior-two-flange loading. Thin-Walled Structures, 50, 76-86.

[38] Uzzaman A, Lim JBP, Nash D, Rhodes J and Young B (2012) Cold-formed steel sections with web openings subjected to web crippling under two-flange loading conditions-part II: parametric study and proposed design equations. Thin-Walled Structures, 56, 79-87.

[39] Uzzaman A, Lim JBP, Nash D, Rhodes J and Young B (2012) Effect of offset web holes on web crippling strength of cold-formed steel channel sections under end-two-flange loading condition. Thin-Walled Structures, 65, 34-48.

[40] Yousefi AM, Uzzaman A, Lim JBP, Clifton GC, Young B (2017) Web crippling strength of cold-formed stainless-steel lipped channels with web perforations under end-two-flange loading. Advances in Structural Engineering, 20(12), 1845-1863.

[41] Bock M, Theofanous M, Dirar S and Raybone P (2019) Assessment of web crippling design provisions for application to proprietary soldier beams. Structures, 20, pp. 147-156.

[42] Sundararajah L, Mahendran M and Keerthan P (2018) Design of SupaCee sections Subjected to web crippling under one-flange load cases, Journal of Structural Engineering 144, 04018222-1 to 04018222-12.

[43] Li H-T and Young B (2018) Design of cold-formed high strength steel tubular sections undergoing web crippling. Thin-Walled Structures, 133, p. 192-205.

[44] Schafer BW, Li Z and Moen CD (2010) Computational modelling of cold-formed steel. ThinWalled Structures 48 (10-11), 752-762.

[45] Zhou F and Young B (2007) Experimental and numerical investigations of cold-formed stainless steel tubular sections subjected to concentrated bearing load, J. Constr. Steel Res. 63 (11), 1452-1466.

[46] Li H-T and Young B (2017) Cold-formed ferritic stainless steel tubular structural members subjected to concentrated bearing loads, Eng. Struct. 145, 392-405.

[47] Zhou F and Young B (2007) Experimental investigation of cold-formed high-strength stainless steel tubular members subjected to combined bending and web crippling. Journal of Structural Engineering (ASCE);133:1027-34.

[48] Gardner L, Talja A and Baddoo NR (2006) Structural design of high-strength austenitic stainless. Thin-Walled Structures, 44, 517-28.

[49] Bock M, Real E and Mirada FX (2015) Statistical evaluation of a new resistance model for cold-formed stainless steel cross-sections subjected to web crippling. International Journal of steel structures, 15(1), 227-244.

[50] Yousefi AM, Lim JBP and Clifton GC (2017) Web bearing capacity of unlipped cold-formed ferritic stainless steel channels with perforated web subject to end-two-flange (ETF) loading. Engineering Structures, 152, pp. 804-818. 
[51] Zhou F and Young B (2008) Aluminum tubular sections subjected to web crippling-part I: tests and finite element analysis. Thin-Walled Struct., 46 (4), pp. 339-351

[52] Zhou F and Young B (2008) Aluminum tubular sections subjected to web crippling-part II: proposed design equations. Thin-Walled Struct., 46 (4), pp. 352-361

[53] Alsanat H, Gunalan S, Guan H, Keerthan P and, Bull J (2019). Experimental study of aluminium lipped channel sections subjected to web crippling under two flange load cases Thin Walled Structures, 141, pp. 460-476.

[54] Hofmeyer H (2005) Cross-section crushing behaviour of hat-sections (Part II: Analytical modelling). Thin-Walled Structures; 43: 1155-1165.

[55] Tsai YM and Crisinel M. (1946). Moment redistribution in continuous profiled sheeting, thinwalled metal structures in buildings. IABSE proceedings, vol. 49. Zürich: IABSE-AIPC-IVBH. pp. 107-14.

[56] Bähr G (1978). Eine einfache Abschätzung der aufnehmbaren Endauflagerkräfte von StahlTrapezblechprofilen. Die Bautechnik, 11, pp. 388-90. [In German].

[57] Reinsch W (1983). Das Kantenbeulen zur rechnerischen Ermittlung von Stahltrapezblechtraäger. Dissertation. Germany: Technische Hochschule Darmstadt.

[58] Vaessen MJ (1995). On the elastic web crippling stiffness of thin-walled cold- formed steel members. M.Sc. thesis. The Netherlands: Department of Structural Design, Eindhoven University of Technology.

[59] Hofmeyer H, Kerstens JGM and Snijder HH (2002) Combined web crippling and bending moment failure of first-generation trapezoidal steel sheeting. Journal of Constructional Steel Research, 58:1509-1529.

[60] Zhou F and Young B (2006) Yield line mechanism analysis on web crippling of cold-formed stainless steel tubular sections under two-flange loading. Engineering Structures , 28, 880-92, 2006. [61] Hofmeyer H, Kerstens JGM, Snijder HH and Bakker MCM (2001) New prediction model for failure of steel sheeting subject to concentrated load (web crippling) and bending. Thin-Walled Structures, 39, 773-96.

[62] Hofmeyer H, Bakker MCM (2008) Sheeting interaction failure, from yield-line to two-strip model. Thin-Walled Structures 46, 839- 847

[63] Bakker MCM, Rosmanit M and Hofmeyer H (2008) Approximate large-deflection analysis of simply supported rectangular plates under transverse loading using plate post-buckling solutions. Thin-Walled Structures 46: 1224-1235.

[64] Hancock GJ and Pham CH (2015) Buckling analysis of thin-walled sections under localised loading using the semi-analytical finite strip method. Thin-Walled Struct. 86, pp. 35-46.

[65] Nguyen VV, Hancock G and Hung Pham C (2017) Analyses of thin-walled sections under localised loading for general end boundary conditions - Part 1: Pre-bucking. Thin-Walled Structures, 119, Pages 956-972.

[66] Nguyen VV, Hancock G and Hung Pham C (2017) New developments in the direct strength method (DSM) for the design of cold-formed steel sections under localised loading. Steel Construction, 10(3):227-233.

[67] Natário P, Silvestre N and Camotim D (2016) Direct strength prediction of web crippling failure of beams under ETF loading. Thin-Walled Structures, 98, p. 360-374.

[68] Duarte APC and Silvestre N (2013) A New Slender-based Approach for the Web Crippling Design of Plain Channel Steel Beams, International Journal of Steel Structures 13, 421-434.

[69] Bock M and Real E (2014) Strength curves for web crippling design of cold-formed stainless steel hat sections, Thin-walled Structures 85, 93-105.

[70] Simulia (2013) ABAQUS Standard User’s Manual, Version 6.14, Rhode Island, USA.

[71] Natário P, Silvestre N and Camotim D (2014) Web crippling failure using quasi-static FE models, Thin-Walled Struct. 84, 34-49.

[72] Bock M, Arrayago I, Real E, Mirambell E (2013) Study of web crippling in ferritic stainless steel cold formed sections, Thin-Walled Struct. 69, 29-44. 
[73] Dos Santos GB, Gardner L and Kucukler M (2018) A method for the numerical derivation of plastic collapse loads, Thin-Walled Structures 124, 258-277.

[74] Southwell RV (1932) On the analysis of experimental observations in problems of elastic stability, Proc. R. Soc. Lond. A: Math., Phys. Eng. Sci. 135 (828) 601-616.

[75] Horne MR, Merchant W (1965) The stability of frames; vol. 9. Oxford.

[76] Doerich C and Rotter J (2011) Accurate Determination of plastic collapse loads from finite element analyses, Journal of pressure Vessel Technology 133 (1) 011202-1 to 011202-10

[77] Heurkens RAJ, Hofmeyer H, Mahendran M and Snijder HH (2018) Direct strength method for web crippling-Lipped channels under EOF and IOF loading, Thin-Walled Structures 123, 126-141. [78] Sundararajah L (2017) Web Crippling Studies of Cold-formed Steel Channel Beams. PhD thesis. Queensland University of Technology.

[79] Ádány S, Visy D and Nagy,R (2018) Constrained shell Finite Element Method, Part 2: application to linear buckling analysis of thin-walled members. Thin-Walled Structures 128: 56-70. 